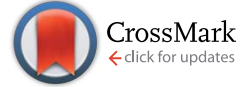

Cite this: J. Mater. Chem. A, 2015, 3, 2012

Received 4th November 2014

Accepted 2nd December 2014

DOI: $10.1039 / c 4 t a 05952 b$

www.rsc.org/MaterialsA

\section{Synthesis of shaped Pt nanoparticles using common anions or small molecules as shape- directing agents: observation of a strong halide or pseudo-halide effect $\dagger$}

\begin{abstract}
Jason A. Michel, \$ William H. Morris III§ and Charles M. Lukehart*
Chemical reduction of Pt(॥) and Pt(IV) salts by $\mathrm{H}_{2}$, hydrazine, or borohydride ion, in the presence of common anions or small molecules is surveyed to discover shape-directing agents suitable for selective formation of Pt metal nanocubes or nanotetrahedra. Surfactants tested include a variety of amino acids, $\mathrm{HSCH}_{2} \mathrm{CO}_{2} \mathrm{H}$, $\mathrm{Ph}_{2} \mathrm{PCH}_{2} \mathrm{CO}_{2} \mathrm{H}$, polycarboxylate species, such as glycolate or tartrate ion, and several common anions (including $\mathrm{CF}_{3} \mathrm{SO}_{3}{ }^{-}, \mathrm{ClO}_{4}{ }^{-}, \mathrm{NO}_{3}{ }^{-}, \mathrm{CO}_{3}{ }^{2-}, \mathrm{PO}_{4}{ }^{3-}, \mathrm{SO}_{4}{ }^{2-}, \mathrm{Cl}^{-}, \mathrm{Br}^{-}$, or I-). Although carboxylate, chloride, bromide, carbonate, nitrate, perchlorate, phosphate, sulfate, or triflate ions show poor shape-directing influence, the presence of hydroxide and iodide ions gives an unexpected halide (or pseudo-halide) effect. Hydrogen reduction of $\left[\mathrm{Pt}(\mathrm{OH})_{6}\right]^{2-}$ ion at basic $\mathrm{pH}$ gives high yields of cubic Pt nanoparticles, while hydrogen reduction of $\left[\mathrm{PtI}_{6}\right]^{2-}$ ion at basic $\mathrm{pH}$ gives high yields of tetrahedral $\mathrm{Pt}$ nanoparticles.
\end{abstract}

\section{Introduction}

Utilizing platinum nanoparticle shape selectivity in chemical catalysis and electrochemical catalysis gives more efficient chemical processing at lower energy cost and is the subject of two recent reviews. ${ }^{\mathbf{1} 2}$ To achieve such benefits, convenient methods of preparing catalytically active Pt metal nanocrystals of desired shape are needed.

A vast literature is available on the synthesis and catalytic reactivity of $\mathrm{Pt}$ metal catalysts, and synthesis strategies for preparing shape- and size-controlled Pt metal colloids have been reviewed. ${ }^{3}$ More recent methods of preparing shaped Pt metal nanoparticles include: Pt-ion reduction by $\mathrm{H}_{2}$ in the presence of carboxylic acid ${ }^{4-6}$ or amine ${ }^{7}$ capping agents; Pt-ion reduction by citrate ion ${ }^{4}$ or formic acid ${ }^{8}$ polyol reduction of $\mathrm{Pt}-$ ion in the presence of polyvinylpyrrolidone (PVP), ${ }^{9} \mathrm{PVP} /$ $\mathrm{AgNO}_{3},{ }^{10} \mathrm{PVP} / \mathrm{NaNO}_{3},{ }^{11}$ or oleylamine ${ }^{12}$ thermal decomposition of organometallic Pt precursors; $;^{13-15} \mathrm{Pt}(\text { acetylacetonate })_{2}$ reduction by oleylamine, ${ }^{\mathbf{1 6}}$ alkenes, ${ }^{17}$ or metal carbonyls in the presence of oleylamine/oleic acid; ${ }^{18}$ photo-induced reduction of $\mathrm{Pt}(\mathrm{Iv})$ ion within micelles; ${ }^{19}$ reduction of Pt-ion with wood nanofibers; ${ }^{20}$ and supported Pt nanoparticles formed by borohydride reduction, ${ }^{21}$ electrochemical reduction, ${ }^{\mathbf{8}}$ or electron-

Department of Chemistry, Vanderbilt University, Nashville, Tennessee 37235, USA. E-mail: chuck.lukehart@vanderbilt.edu; Fax: +1 615 3431234; Tel: +1 6153222935 $\uparrow$ Electronic supplementary information (ESI) available: See experimental procedures and TEM images. See DOI: 10.1039/c4ta05952b

‡ Present address: Department of Chemistry, George Washington University, Washington, DC, 20052, USA.

$\S$ Present address: Kemira, Atlanta, GA, 30313, USA. beam deposition. ${ }^{22}$ Control of Pt nanoparticle shape is usually achieved by the choice of surfactant or shape-directing agent used and by careful regulation of experimental conditions, such as surfactant or shape-directing agent concentration, $\mathrm{pH}$, temperature, ambient light intensity, and reaction time. A wide variety of $\mathrm{Pt}$ particle shapes have been prepared through experimental control of metal particle nucleation and growth events.

Recent reports of chemical ${ }^{23-28}$ or electrochemical ${ }^{29-37}$ catalysis employing shaped Pt metal nanoparticles commonly utilize Pt nanoparticles prepared by colloidal synthesis strategies using polymeric surfactants, such as PVP or polyacrylic acid (PAA), as shape-directing agents. While these synthesis methods are convenient to perform and provide shaped Pt metal nanoparticles at sufficient mass scale, complete removal of surfactant material remains a challenge. ${ }^{38}$ While extensive solvent washing $^{\mathbf{3 9 , 4 0}}$ or electrochemical stripping ${ }^{\mathbf{4 1}}$ procedures reduce surfactant contamination, UV irradiation treatments ${ }^{\mathbf{4 0 , 4 2}}$ lead to Pt nanoparticle aggregation or surface damage.

In this study, common anions or small molecules are surveyed as possible shaped-directing agents with the goal of finding polymer-free methods for convenient preparation of shaped Pt nanoparticles. Given the known catalytic reactivity differences of $\mathrm{Pt}(100)$ and $\mathrm{Pt}(111)$ surfaces, formation of $\mathrm{Pt}$ metal nanocubes or nanotetrahedra is of primary interest. The outcome of this study was unexpected. Carboxylate, polycarboxylate, hydroxy-, amino-, phosphino-, or mercaptocarboxylate anions all showed poor shape-directing influence (even though such functional groups are present in shape-directing polymeric surfactants) as did chloride, bromide, carbonate, 
nitrate, perchlorate, phosphate, sulfate, or triflate ions. However, hydroxide and iodide anions serve as endogenous shape-directing agents in the $\mathrm{H}_{2}$ reduction of $\mathrm{Pt}(\mathrm{Iv})$ complexes to form, respectively, $\mathrm{Pt}$ nanocubes and nanotetrahedra. This strong "halide (or pseudo-halide) effect" is surprising, though not unprecedented. A recent review of the complex role that halide ions play in controlling anisotropic noble metal nanocrystal growth emphasizes the need for additional investigation of this phenomenon. ${ }^{43}$

\section{Experimental}

\section{Reagents and general methods}

All reagents were used as purchased without further purification. Potassium tetrachloroplatinate(II), 99.9\%, was purchased from Strem Chemicals. Potassium hexaiodoplatinate(Iv), 99.9\%, potassium iodide, 99\%, $\beta$-alanine, 98\%, sodium glycolate, 97\%, glycolic acid, 99\%, and stearic acid, 95\%, were purchased from
Sigma Aldrich. Dihydrogen hexahydroxyplatinate(Iv), 99.9\%, and potassium tartrate, 99\%, were purchased from Alfa Aesar. Glycine, 97\%, and perchloric acid, 70\%, were purchased from Fisher. Sarcosine, 98\%, N,N-dimethylglycine, 97\%, and betaine (inner salt), 98\%, and tetrabutylammonium hydroxide solution, $40 \% \mathrm{w} / \mathrm{w}$, were purchased from Acros. Potassium hydroxide, $85 \%$, and hydrochloric acid, 38\%, were purchased from EMD. Vulcan XC-72R and Black Pearls 2000 were purchased from Cabot. Water was singly distilled in air over $5 \% \mathrm{NaOH}$ and $2.5 \%$ $\mathrm{KMnO}_{4}$ by weight.

All routine transmission electron microscopy (TEM) was carried out on a Philips CM-20 TEM equipped with a $\mathrm{LaB}_{6}$ thermionic electron source and an energy dispersive spectrometer (EDS) and operating at $200 \mathrm{kV}$ accelerating voltage. High-resolution transmission electron microscopy (HR-TEM) was performed on a Philips CM-30 TEM equipped with a $\mathrm{LaB}_{6}$ thermionic emitter and operating at $300 \mathrm{kV}$. Samples for TEM were dropped onto carbon-coated grids and allowed to dry in

Table 1 Colloidal Pt nanoparticle syntheses performed ${ }^{a}$



${ }^{a} \mathrm{THF}=$ tetrahydrofuran; $\mathrm{RT}=$ room temperature; DPPA = diphenylphosphinoacetic acid; $\mathrm{T}_{\mathrm{d}}=$ tetrahedral; $\mathrm{O}_{\mathrm{h}}=$ octahedral; "trun" $=$ truncated. 
air. All powder X-ray diffraction (XRD) was carried out on a Scintag X-1 XRD in the $\theta-\theta$ configuration and equipped with a Peltier-cooled solid-state detector. Samples for XRD were deposited onto a $\mathrm{Si}(510)$ plate and scanned in air. Ultravioletvisible spectroscopy (UV-Vis) was carried out using a HewlettPackard 8452A photodiode array spectrophotometer.

\section{Pt colloid syntheses}

Formation of $\mathrm{Pt}$ metal colloids were surveyed using: $\mathrm{Pt}_{2}\left(\mathrm{C}_{2} \mathrm{H}_{4}\right)_{2} \mathrm{Cl}_{4}, \quad \mathrm{~K}_{2}\left[\mathrm{PtCl}_{4}\right], \quad \mathrm{PtI}_{2}$ (glycinato $)_{2}, \quad \mathrm{~K}_{2}\left[\mathrm{PtI}_{6}\right], \quad$ or $\mathrm{H}_{2}\left[\mathrm{Pt}(\mathrm{OH})_{6}\right]$ as sources of $\mathrm{Pt}$ ion; aqueous or non-aqueous solvent; $\mathrm{H}_{2}$, hydrazine $\left(\mathrm{N}_{2} \mathrm{H}_{4}\right)$ hydrate, or $\mathrm{NaBH}_{4}$ as reducing agents; and a variety of carboxylates, amino acids, $\mathrm{Ph}_{2} \mathrm{PCH}_{2} \mathrm{CO}_{2} \mathrm{H}$, $\mathrm{HSCH}_{2} \mathrm{CO}_{2} \mathrm{H}$, or common anions $\left(\mathrm{CF}_{3} \mathrm{SO}_{3}{ }^{-}, \mathrm{ClO}_{4}{ }^{-}, \mathrm{NO}_{3}{ }^{-}, \mathrm{CO}_{3}{ }^{2-}\right.$, $\mathrm{PO}_{4}{ }^{3-}, \mathrm{SO}_{4}{ }^{2-}, \mathrm{Cl}^{-}, \mathrm{Br}^{-}$, or $\mathrm{I}^{-}$) as shape-directing agents. A listing of syntheses performed along with nanoparticle shape outcomes is provided in Table 1. Detailed synthesis procedures are available as ESI. $\dagger$ In a typical synthesis, Pt reagent is dissolved in water at a desired temperature and $\mathrm{pH}$ in the presence of a surface-directing agent under subdued lighting. Reducing agent is introduced, and the reaction is monitored until a golden yellow or brown color develops. Various control syntheses were conducted, as discussed below.

\section{Results and discussion}

\section{Pt colloid syntheses}

Formation of shaped Pt nanoparticles by El-Sayed, et al., ${ }^{\mathbf{4 4}}$ and shaped $\mathrm{Ni}$ and Pd nanoparticles by Reetz, et al., ${ }^{\mathbf{4 5}}$ using polycarboxylate or $\alpha$-hydroxycarboxylate shape-directing agents prompted a survey of Pt-ion reductions in the presence of simple bi-functional or poly-functional carboxylate ions. Reaction of $\mathrm{Pt}_{2}\left(\mathrm{C}_{2} \mathrm{H}_{4}\right)_{2} \mathrm{Cl}_{4}$ and $\left[\mathrm{Bu}_{4} \mathrm{~N}\right]$ glycolate in THF solution, using glycolate ion as both reducing agent and shape-directing agent, produces Pt nanoparticles of heterogeneous shapes (see ESI, Fig. S1 $\uparrow$ ), suggesting that the Reetz method does not apply to Ption reduction. Reduction of $\left[\mathrm{PtCl}_{4}\right]^{2-}$ in water by either glycolate or tartrate ion requires elevated temperatures and gives poorly faceted, highly agglomerated $\mathrm{Pt}$ nanoparticles (see ESI, Fig. $\mathrm{S} 2 \dagger)$. Reduction of aqueous $\left[\mathrm{PtCl}_{4}\right]^{2-}$ solutions at room temperature using $\mathrm{H}_{2}$ as reducing agent and either glycolate or tartrate ion as shape-directing agent gives less agglomerated Pt nanoparticles exhibiting heterogeneous shapes but includes some identifiable cubic and tetrahedral particles (see ESI, Fig. S3 $\uparrow$ ). Hydrazine reduction of $\left[\mathrm{PtCl}_{4}\right]^{2-}$ within a stearic acid/ water-in-oil emulsion at room temperature forms relatively large (ave. dia. $\approx 20 \mathrm{~nm}$ ), spheroidal $\mathrm{Pt}$ nanoparticles that apparently form within a poly-carboxylate, spherical micelle (see ESI, Fig. S4 $\dagger$ ).

Amino acid conjugate bases represent another class of potentially bifunctional carboxylate shape-directing agents. Basic $\mathrm{pH}$ is required to ensure a high degree of deprotonation (glycine; $\mathrm{p} K_{\mathrm{a}}=9.60$ ). When using glycine as a possible shapedirecting agent, Pt colloid formation is accelerated by in situ displacement of chloro ligands of $\mathrm{K}_{2}\left[\mathrm{PtCl}_{4}\right]$ by iodide ion (KI) giving to form (glycinato) ${ }_{2} \mathrm{PtI}_{2} \cdot \mathrm{H}_{2}$ reduction of (glycinato) ${ }_{2} \mathrm{PtI}_{2}$ at $\mathrm{pH} 10.5$ yields highly faceted Pt nanoparticles exhibiting a variety of shapes with sizes ranging from 5-20 nm (see ESI, Fig. S5 $\dagger$ ). Unfortunately, this method is not very shape selective. Control reactions indicate that while varying free glycine concentration has little effect on Pt nanoparticle shape, variation in reaction $\mathrm{pH}$ has a dramatic effect. Pt particles formed at pH 6 are sufficiently small $(1-3 \mathrm{~nm})$ that particle shape is not easily discerned (see ESI, Fig. S6†). Pt particles formed at $\mathrm{pH} 3.5$ exhibit a variety of shapes, though the most common are multitetrahedral, star-like shapes and Pt multi-pods (see ESI, Fig. S7†). ${ }^{\mathbf{4 6 , 4 7}}$ While such complex nanoparticle shapes are interesting, they possess a mixture of surface facets and are not desirable for shape-selective catalysis.

Diphenylphosphinoacetic acid (DPPA) and mercaptoacetic acid proved to have only limited usefulness as shape-directing agents. DPPA is soluble only at very high $\mathrm{pH}$, which destabilizes Pt colloids, leading to particle precipitation. Mercaptoacetic acid apparently binds sufficiently strongly to Pt ion that $\mathrm{NaBH}_{4}$ is required as reducing agent. The presence of DPPA produces faceted Pt nanoparticles as a mixture of truncated tetrahedral and cubo-octahedral shapes, while mercaptoacetic acid gives very small Pt particles (1-2 $\mathrm{nm}$ ) of irregular shape (see ESI, Fig. S8†).

Proline, serine, and phenylalanine are also poor shapedirecting agents. Each of these amino acids produces 2-5 nm Pt particles having a variety of spheroidal and oblong shapes (see ESI, Fig. S9†).

$\mathrm{N}$-substituted amino acids [sarcosine ( $\mathrm{N}$-methylglycine), $\mathrm{N}, \mathrm{N}$ dimethylglycine, betaine (inner salt, 2-trimethylammonioacetate), and $\beta$-alanine (3-aminopropanoic acid)] represent a series of shape-directing agents containing $\alpha$-amino groups having different Lewis and Brønsted basicities. $\mathrm{H}_{2}$ reduction of $\mathrm{K}_{2}\left[\mathrm{PtCl}_{4}\right]$ solutions in the presence of sarcosine, betaine, or $\beta$-alanine gives Pt colloids of primarily spheroidal or oblong shape or particles too small for easy shape identification. However, $\mathrm{H}_{2}$ reduction of $\left[\mathrm{PtCl}_{4}\right]^{2-}$ in the presence of $\mathrm{N}, \mathrm{N}$ dimethylglycine is accelerated by addition of eight equivalents of KI affording mainly tetrahedral Pt nanoparticles along with far fewer nanocubes than that observed when using glycine. This observation suggests a possible special influence by iodide ion. The presence of $\mathrm{N}, \mathrm{N}$-dimethylglycine gives far fewer irregular shapes and a nearly complete absence of very small nanoparticles (see ESI, Fig. S10 $)$. $\mathrm{H}_{2}$ reduction of basic solutions of $\mathrm{K}_{2}\left[\mathrm{PtI}_{6}\right]$ in the presence of glycine, sarcosine, $\mathrm{N}, \mathrm{N}$ dimethylglycine, betaine, or $\beta$-alanine forms tetrahedral $\mathrm{Pt}$ nanoparticles as primary product, and in some cases, almost entirely Pt nanotetrahedra (see ESI, Fig. S11†).

Quite unexpectedly, however, control experiments reveal that Pt nanotetrahedra are formed by $\mathrm{H}_{2}$ reduction of basic $\left[\mathrm{PtI}_{6}\right]^{2-}$ solutions even in the absence of any intentional surfacedirecting agent (see ESI, Fig. S11F $\dagger$ )! Likewise, $\mathrm{H}_{2}$ reduction of basic solutions of $\mathrm{K}_{2}\left[\mathrm{Pt}(\mathrm{OH})_{6}\right]$ in the absence of iodide ion and any other intentional shape-directing agent gives predominantly Pt nanocubes (see ESI, Fig. S12 \& S13†). Fig. 1 \& 2 show TEM and HR-TEM images of Pt nanocubes and nanotetrahedra prepared by $\mathrm{H}_{2}$ reduction of $\left[\mathrm{Pt}(\mathrm{OH})_{6}\right]^{2-}$ and $\left[\mathrm{PtI}_{6}\right]^{2-}$, respectively. HR-TEM images reveal lattice fringe spacings of $0.20 \mathrm{~nm}$ 


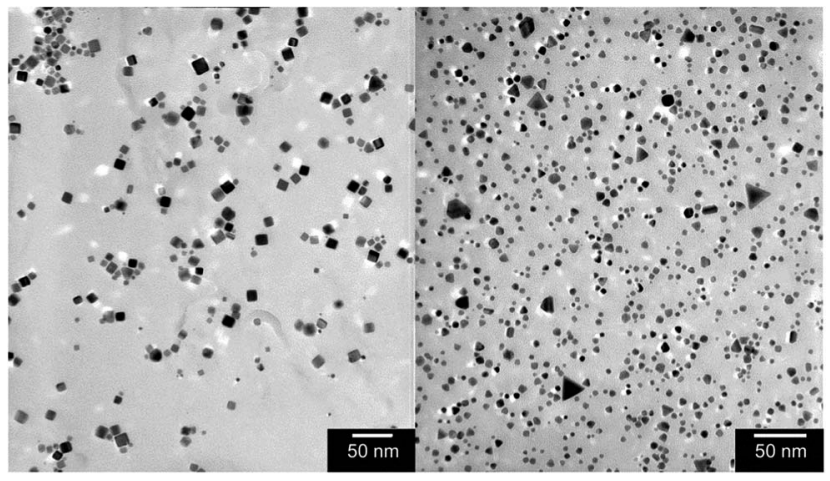

Fig. 1 As-prepared Pt nanoparticles deposited from aqueous colloids. (Left) Cubic Pt nanoparticles prepared by $\mathrm{H}_{2}$ reduction of $\left[\mathrm{Pt}(\mathrm{OH})_{6}\right]^{2-}$ at $\mathrm{pH}$ 9.7. Note the presence of a minority of tetrahedra and cubooctahedra. (Right) Tetrahedral Pt nanoparticles prepared by $\mathrm{H}_{2}$ reduction of $\left[\mathrm{PtI}_{6}\right]^{2-}$ at $\mathrm{pH} 10$. Many truncated tetrahedra are present, but cubes are rare.

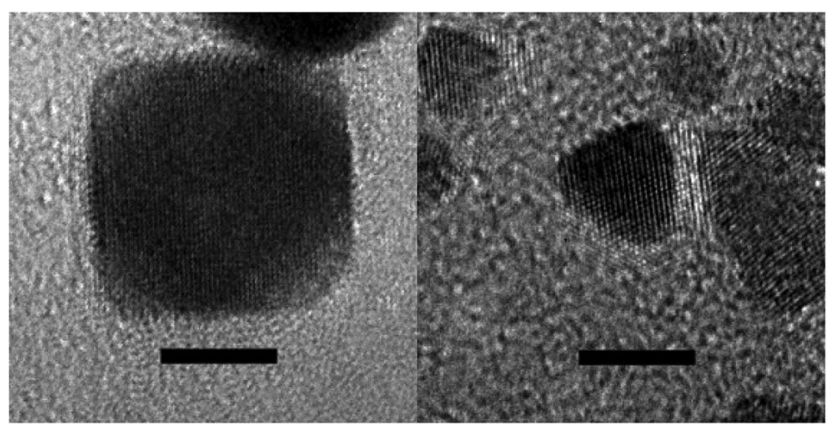

Fig. 2 High-resolution TEM images of a typical cubic Pt nanoparticle (left image) and of a typical tetrahedral Pt nanoparticle (right image). Scale bars $=5 \mathrm{~nm}$.

for cubic Pt nanoparticles and of $0.23 \mathrm{~nm}$ for tetrahedral $\mathrm{Pt}$ nanoparticles consistent with $\{100\}$ and $\{111\} d$-spacings reported by others for similarly shaped Pt nanoparticles. ${ }^{48}$ The expected $\{111\}$ cross fringe pattern is also observed for tetrahedral Pt nanoparticles. Given that hydroxo and iodo ligands serve as highly selective shape-directing agents in $\mathrm{H}_{2}$ reduction of $\mathrm{Pt}(\mathrm{Iv})$ ion, knowing the kinetic stability of $\left[\mathrm{Pt}(\mathrm{OH})_{6}\right]^{2-}$ and $\left[\mathrm{PtI}_{6}\right]^{2-}$ precursor complexes in basic aqueous solutions and in the presence of $\mathrm{H}_{2}$ becomes important.

\section{Kinetic stability and $\mathrm{H}_{2}$ reduction of $\left[\mathrm{Pt}(\mathrm{OH})_{6}\right]^{2-}$ solutions}

As shown in Fig. 3, the UV-Vis spectrum of $\left[\mathrm{Pt}(\mathrm{OH})_{6}\right]^{2-}$ is dominated by a single absorption band centered near $200 \mathrm{~nm}$, characteristic of an intense charge-transfer band. A similar band appears at $262 \mathrm{~nm}$ in $\left[\mathrm{PtCl}_{6}\right]^{2-}$ ion..$^{49}\left[\mathrm{Pt}(\mathrm{OH})_{6}\right]^{2-}$ solutions appear visibly to be unaffected by the presence of iodide ion. UV-Vis spectra of mixtures of solutions containing $\left[\mathrm{Pt}(\mathrm{OH})_{6}\right]^{2-}$ and iodide ion show no new bands above $260 \mathrm{~nm}$ over two days. Intense absorption centered near $225 \mathrm{~nm}$ by iodide ion obscures UV-Vis band detection from ca. 190-260 $\mathrm{nm}^{.0}$

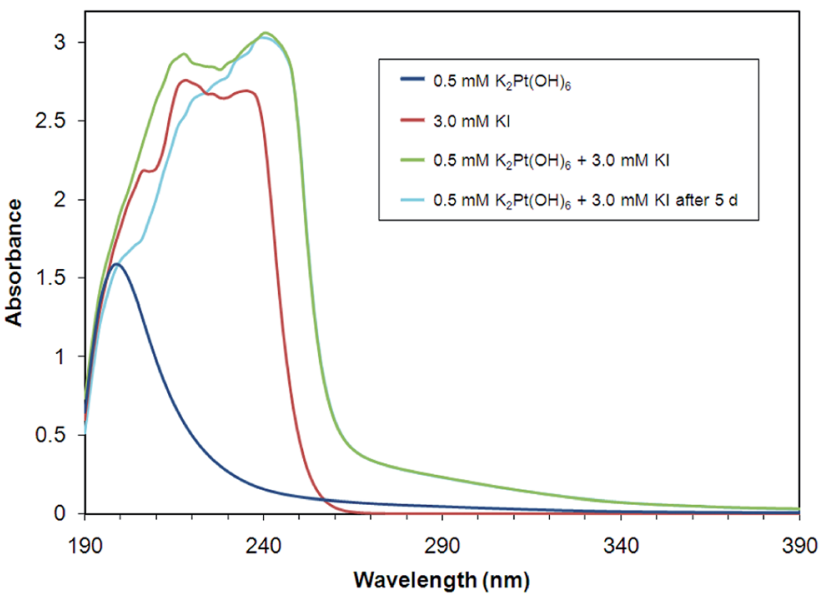

Fig. 3 UV-Vis spectra of $\mathrm{K}_{2}\left[\mathrm{Pt}(\mathrm{OH})_{6}\right]$ and $\mathrm{KI}$ aqueous solutions and a 1 : 6 molar mixture of $\mathrm{K}_{2}\left[\mathrm{Pt}(\mathrm{OH})_{6}\right]$ and $\mathrm{KI}$ over a five-day period.

$\mathrm{H}_{2}$ reduction of aqueous $\left[\mathrm{Pt}(\mathrm{OH})_{6}\right]^{2-}$ occurs with lengthy induction periods that are strongly pH dependent ( $c a .7$ days at $\mathrm{pH} 9.7 ; c a .20$ days at pH 10.2). Pt nanoparticle growth is visibly observed as the emergence and gradual darkening of a deep golden color associated with formation of well-dispersed $\mathrm{Pt}$ nanoparticles. Complete reaction is achieved after $36 \mathrm{~h}$. Even in the presence of six equivalents of added iodide ion, $\mathrm{H}_{2}$ reduction of $\left[\mathrm{Pt}(\mathrm{OH})_{6}\right]^{2-}$ consistently forms predominantly $\mathrm{Pt}$ nanocubes.

The apparent rate of $\mathrm{H}_{2}$ reduction of aqueous $\left[\mathrm{Pt}(\mathrm{OH})_{6}\right]^{2-}$ is significantly increased when amino acids or other ionic species are present but substantial loss of shape selectivity occurs. In the presence of weakly coordinating anions, such as triflate, nitrate, perchlorate, and carbonate, cubo-octahedral Pt nanoparticles are primarily formed (see ESI, Fig. S13†). Hydroxide ion appears to inhibit Pt particle nucleation giving relatively large particles and favors formation of (100) facets - an effect diminished somewhat by the presence of other ions (vide infra).

\section{Kinetic stability and $\mathrm{H}_{2}$ reduction of $\left[\mathrm{PtI}_{6}\right]^{2-}$ solutions at basic pH}

$\left[\mathrm{PtI}_{6}\right]^{2-}$ solutions in neutral or acidic water readily decompose to form metallic Pt and are highly light sensitive. At basic pH, rapid reaction is evident from UV-Vis spectral changes, as shown in Fig. 4. Initial spectra reveal three absorption bands near $340 \mathrm{~nm}, 440 \mathrm{~nm}$, and $490 \mathrm{~nm}$ characteristic of $\left[\mathrm{PtI}_{6}\right]^{2-}$ aqueous solutions..$^{50}$ These bands disappear with a first-order rate constant of $c a .15 \times 10^{-3} \mathrm{~s}^{-1}\left(\tau_{1 / 2}=c a .46 \mathrm{~s}\right.$; determined from the rate of disappearance of the $490 \mathrm{~nm}$ band) with concomitant appearance of a single band centered at $c a .390 \mathrm{~nm}$ and a recognizable isosbestic point at $c a .375 \mathrm{~nm}$. A previous kinetics study of $\left[\mathrm{PtI}_{6}\right]^{2-}$ ion hydrolysis over a pH range of 610.5 identified a first-stage iodide/water ligand exchange reaction forming $\left[\mathrm{PtI}_{5}\left(\mathrm{H}_{2} \mathrm{O}\right)\right]^{-}$showing nearly identical spectral changes and a similar first-order rate constant of $16.5 \times 10^{-3}$ $\mathrm{s}^{-1}$ at pH 10 and $21.0{ }^{\circ} \mathrm{C}^{.50}$ Given that $\left[\mathrm{PtI}_{5}\left(\mathrm{H}_{2} \mathrm{O}\right)\right]^{-}$has a firstionization $\mathrm{p} K_{\mathrm{a}}$ value of 8.55 at $25.5{ }^{\circ} \mathrm{C},{ }^{50}$ this complex would be 


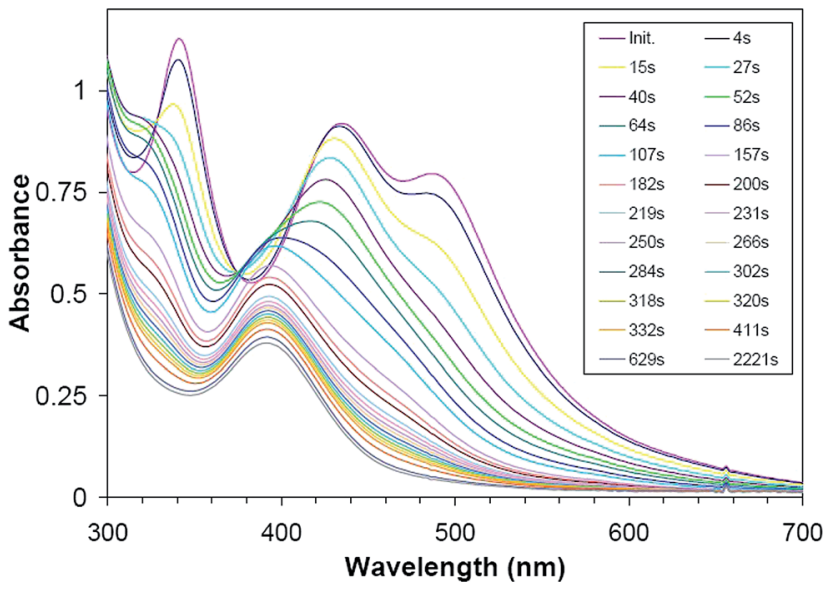

Fig. 4 UV-Vis spectra collected over various reaction time intervals showing overall kinetic displacement of one iodo ligand of $\left[\mathrm{PtI}_{6}\right]^{2-}$ by hydroxide ion at $\mathrm{pH} 10$ and $22{ }^{\circ} \mathrm{C}$ giving $\left[\mathrm{PtI}_{5}(\mathrm{OH})\right]^{2-}$ as product.

96\% ionized at $\mathrm{pH} 10$ giving $\left[\mathrm{PtI}_{5}(\mathrm{OH})\right]^{2-}$ ion as the solution species assigned to the product absorption band centered at $c a$. $390 \mathrm{~nm}$.

The relatively high lability of iodo ligands in $\mathrm{Pt}(\mathrm{Iv})$ complexes leads to very rapid reduction by $\mathrm{H}_{2}$. Upon addition to basic water, the deep violet color of $\left[\mathrm{PtI}_{6}\right]^{2-}$ begins to change to orange as $\mathrm{OH}^{-}$begins to displace $\mathrm{I}^{-}$. Typically, the orange color of the $\left[\mathrm{PtI}_{6-x} \mathrm{OH}_{x}\right]^{2-}$ precursor solutions begins to change within minutes of $\mathrm{H}_{2}$ introduction, and $\mathrm{Pt}$ nanoparticle formation is complete within $2 \mathrm{~h}$. To achieve high yields of tetrahedral $\mathrm{Pt}$ nanoparticles at $\mathrm{pH} 10, \mathrm{H}_{2}$ must be introduced within a few minutes of the addition of $\mathrm{K}_{2} \mathrm{PtI}_{6}$ salt to basic water. The shape selectivity of Pt nanotetrahedra appears to be highly dependent on the composition of solution species during nanoparticle nucleation. If the reaction solution is allowed to reach near equilibrium before exposure to $\mathrm{H}_{2}$, a dramatic decrease in the number of tetrahedra is observed along with an increase in the number of cubo-octahedra and cubic shapes. Detailed kinetics study of $\left[\mathrm{PtI}_{6}\right]^{2-}$ hydrolysis at $\mathrm{pH} 6$ reveals a complex three-stage reaction mechanism involving hydrolysis and redox reactions generating as many as eight different $\mathrm{Pt}$ solution species. ${ }^{50}$

\section{Reduction of $\left[\mathrm{Pt}(\mathrm{OH})_{6}\right]^{2-}$ or $\left[\mathrm{PtI}_{6}\right]^{2-}$ solutions using hydrazine or borohydride}

Attempts to accelerate Pt nanoparticle formation by using stronger reducing agents, such as hydrazine and borohydride ion, leads to diminished shape selectivity with the following outcomes: (1) hydrazine or borohydride accelerate Pt nanoparticle formation relative to $\mathrm{H}_{2}$ reduction but without a reduction in $\mathrm{Pt}$ average nanoparticle size; (2) reduction of $\left[\mathrm{Pt}(\mathrm{OH})_{6}\right]^{2-}$ at increasing concentrations of hydrazine gives higher number fractions of Pt nanotetrahedra, cubo-octahedra, and nanorods (see ESI, Fig. S14†); (3) hydrazine reductions of $\left[\mathrm{Pt}(\mathrm{OH})_{6}\right]^{2-}$ in the presence of chloride, bromide, carbonate, phosphate, sulfate, or triflate ions give similar mixtures of Pt nanoparticle shapes, including worm-like nanowires (see ESI,

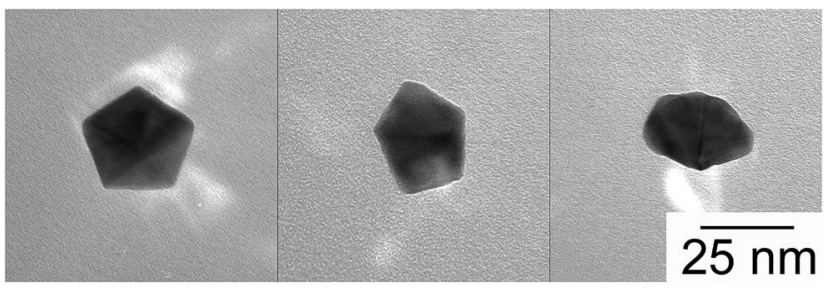

Fig. 5 Three views, at different angles of TEM stage tilt, of a particularly large decahedron formed by reduction of $\left[\mathrm{Pt}(\mathrm{OH})_{6}\right]^{2-}$ with borohydride ion

Fig. S15†); and, (4) borohydride reduction of $\left[\mathrm{Pt}(\mathrm{OH})_{6}\right]^{2-}$ gives primarily $\mathrm{Pt}$ nanocubo-octahedra along with small number fractions of octahedral and decahedral (pentagonal bipyramidal) nanoparticles (see ESI, Fig. S16†). Images of a particularly large Pt nanodecahedron are shown in Fig. 5.

\section{Roles of hydroxide and iodide ions in influencing $\mathbf{P t}$ nanoparticle shape}

Given that the adsorption enthalpy of hydroxide ion on a Pt(100) surface $\left(c a .-280 \mathrm{~kJ} \mathrm{~mol}^{-1}\right),{ }^{51}$ is greater than that on a $\operatorname{Pt}(111)$ surface $\left(c a .-255 \mathrm{~kJ} \mathrm{~mol}^{-1}\right),{ }^{52}$ formation of cubic Pt nanoparticles might be expected from $\mathrm{H}_{2}$ reduction of $\left[\mathrm{Pt}(\mathrm{OH})_{6}\right]^{2-}$ at basic $\mathrm{pH}$. While hydroxide adsorption enthalpy on $\mathrm{Pt}(111)$ surfaces decreases with increasing surface coverage, this effect is not observed on $\mathrm{Pt}(100)$ surfaces, further supporting formation of Pt nanocubes at basic $\mathrm{pH} .{ }^{51}$ This surface coverage effect is attributed to differences in hydrogen bonding networks established among $\mathrm{OH}$ groups on these two surfaces and to the fact that a $\mathrm{OH}-\mathrm{H}_{2} \mathrm{O}$ hydrogen bond is much stronger than a $\mathrm{OH}-\mathrm{OH}$ hydrogen bond. Species that disrupt hydrogen bonding networks at $\mathrm{Pt}(100)$ surfaces could inhibit selective growth of that surface, possibly explaining the formation of Pt cubooctahedral and tetrahedral nanoparticle shapes when Pt-ion reduction occurs in the presence of simple anions or amino acid additives.

Iodide ion binds more strongly to top and bridge sites of $\mathrm{Pt}(111)$ surfaces (bonding enthalpies of $c a .-245 \mathrm{~kJ} \mathrm{~mol}^{-1}$ and $-286 \mathrm{~kJ} \mathrm{~mol}^{-1}$, respectively $)^{53}$ than to similar sites of $\mathrm{Pt}(100)$ surfaces (bonding enthalpies of $c a .-225 \mathrm{~kJ} \mathrm{~mol}^{-1}$ and $-265 \mathrm{~kJ}$ mol ${ }^{-1}$, respectively). ${ }^{52}$ During $\mathrm{H}_{2}$ reduction of $\left[\mathrm{PtI}_{6}\right]^{2-}$, iodide ions would presumably establish monolayer coverage on the surface of a growing nanoparticle, thus preventing adsorption of other species and enforcing retention of (111) surfaces to give Pt nanotetrahedra.

\section{Conclusions}

Efficient methods of preparing cubic or tetrahedral Pt nanoparticles via solution reduction of common Pt(II) or Pt(IV) salts in the absence of polymeric surfactants have been found. Hydrogen reduction of $\left[\mathrm{Pt}(\mathrm{OH})_{6}\right]^{2-}$ ion at basic $\mathrm{pH}$ gives high yields of cubic Pt nanoparticles, while hydrogen reduction of $\left[\mathrm{PtI}_{6}\right]^{2-}$ ion at basic $\mathrm{pH}$ gives high yields of tetrahedral $\mathrm{Pt}$ nanoparticles. Although minor shape effects are observed when 
Pt salts are reduced in the presence of simple carboxylate species, amino acids, or common inorganic ions, the exceptional shape effect of hydroxide ion and iodide ion is noteworthy. The presence of surface-bound hydroxide or iodide ions on Pt nanoparticle surface sites can be mitigated to promote chemical or electrochemical catalysis. Hydroxylated Pt metal surfaces are catalytically active toward methanol oxidation, ${ }^{\mathbf{5 4}}$ and CO displacement of chemisorbed iodine on pristine $\mathrm{Pt}$ metal surfaces is used in protocols for cleaning Pt metal surfaces. ${ }^{55,56}$ Although atomic-level understanding of how hydroxide and iodide direct $\mathrm{Pt}$ nanoparticle growth toward cubic or tetrahedral shapes, respectively, at basic $\mathrm{pH}$ has not been determined, it is hoped that shaped Pt metal nanoparticles prepared by this method prove to be effective catalysts under convenient operating conditions.

\section{Acknowledgements}

Financial support from the DuPont Science \& Engineering University Grant Program and from the Honda Initiation Grant Award Program (C.M.L.) is gratefully acknowledged. We thank Dr James Bentley for access to HR-TEM instrumentation at the Oak Ridge National Laboratory.

\section{References}

1 I. Lee and F. Zaera, Top. Catal., 2013, 56, 1284-1298.

2 Z. Peng and H. Yang, Nano Today, 2009, 4, 143-164.

3 C. Coutanceau, P. Urchaga, S. Brimaud and S. Baranton, Electrocatalysis, 2012, 3, 75-87.

4 G. A. Attard, J.-Y. Ye, P. Jenkins, F. J. Vidal-Iglesias, E. Herrero and S.-G. Sun, J. Electroanal. Chem., 2013, 688, 249-256.

5 J. Zeng, J. Mater. Chem., 2012, 22, 3170-3176.

6 M. A. El-Sayed and J. W. Yoo, ChemCatChem, 2010, 2, 268271.

7 L.-M. Lacroix, C. Gatel, R. Arenal, C. Garcia, S. Lachaize, T. Blon, B. Warot-Fonrose, E. Snoeck, B. Chaudret and G. Viau, Angew. Chem., Int. Ed., 2012, 51, 4690-4694.

8 S. Sattayasamitsathit, Y. Gu, K. Kaufmann, W. Jia, X. Xiao, M. Rodriguez, S. Minteer, J. Cha, D. B. Burckel and C. Wang, et. al., J. Mater. Chem. A, 2013, 1, 1639-1645.

9 S. Alayoglu, C. Aliaga, C. Sprung and G. A. Somorjai, Catal. Lett., 2011, 141, 914-924.

10 N. V. Long, C. M. Thi, M. Nogami and M. Ohtaki, New J. Chem., 2012, 36, 1320-1334.

11 Y. Yang, Z. Huang, D. Li and M. Nogami, Proc. SPIE, 2010, 7658, 76580H.

12 N. Shukla, M. M. Nigra, M. A. Bartel, T. Nuhfer, C. Phatak and J. A. Gellman, Catal. Lett., 2010, 140, 85-89.

13 K. Pelzer, M. Haevecker, M. Boualleg, J.-P. Candy and J.-M. Basset, Angew. Chem., Int. Ed., 2011, 50, 5170-5173.

14 K. Mase, H. Kondo, S. Kondo, M. Hori, M. Hiramatsu and H. Kano, Appl. Phys. Lett., 2011, 98, 193108.

15 M. R. Axet, K. Philippot, B. Chaudret, M. Cabie, S. Giorgio and C. R. Henry, Small, 2011, 7, 235-241.

16 X. Gong, Y. Yang, L. Zhang, C. Zou, P. Cai, G. Chen and S. Huang, J. Colloid Interface Sci., 2010, 352, 379-385.
17 C. Kim, S. S. Kim, S. Yang, J. W. Han and H. Lee, Chem. Commun., 2012, 48, 6396-6398.

18 Y. Kang, J. B. Pyo, X. Ye, R. E. Diaz, T. R. Gordon, E. A. Stach and C. B. Murray, ACS Nano, 2013, 7, 645-653.

19 S. Kundu and H. Liang, Langmuir, 2010, 26, 6720-6727.

20 X. Lin, M. Wu, D. Wu, S. Kuga, T. Endo and Y. Huang, Green Chem., 2011, 13, 283-287.

21 Y. He and H. Cui, Chem.-Eur. J., 2012, 18, 4823-4826.

22 V. Komanicky, H. Iddir, K.-C. Chang, A. Menzel, G. Karapetrov, D. C. Hennessy, P. Zapol and H. You, Electrochim. Acta, 2010, 55, 7934-7938.

23 V. V. Pushkarev, N. Musselwhite, K. An, S. Alayoglu and G. A. Somorjai, Nano Lett., 2012, 12, 5196-5201.

24 S. Takeda, Appl. Phys. Express, 2011, 4, 065001.

25 F. Vines and A. Goerling, Angew. Chem., Int. Ed., 2011, 50, 4611-4614.

26 S. Mostafa, F. Behafarid, J. R. Croy, L. K. Ono, L. Li, J. C. Yang, A. I. Frenkel and B. R. Cuenya, J. Am. Chem. Soc., 2010, 132, 15714-15719.

27 I. Lee and F. Zaera, J. Catal., 2010, 269, 359-366.

28 A. M. T. Silva, B. F. Machado, H. T. Helder, J. L. Figueiredo, G. Drazic and F. Goran, J. Nanopart. Res., 2010, 12, 121-133.

29 P. Urchaga, S. Baranton, C. Coutanceau and G. Jerkiewicz, Langmuir, 2012, 28, 13094-13104.

30 F. J. Vidal-Iglesias, R. M. Aran-Ais, J. Solla-Gullon, E. Herrero and J. M. Feliu, ACS Catal., 2012, 2, 901-910.

31 O. Guillen-Villafuerte, G. Garcia, A. G. Orive, B. Anula, A. H. Creus and E. Pastor, Electrocatalysis, 2011, 2, 231-241.

32 M.-H. Shao, A. Peles and K. Shoemaker, Nano Lett., 2011, 11, 3714-3719.

33 I. J. Hsu, D. V. Esposito, E. G. Mahoney, A. Black and J. G. Chen, J. Power Sources, 2011, 196, 8307-8312.

34 C. Susut and Y. Y. J. Tong, Electrocatalysis, 2011, 2, 75-81.

35 K. R. Beyerlein, J. Solla-Gullon, E. Herrero, E. Garnier, F. Pailloux, M. Leoni, P. Scardi, R. L. Snyder, A. Aldaz and J. M. Feliu, Mater. Sci. Eng., A, 2010, 528, 83-90.

36 V. Grozovski, J. Solla-Gullon, V. Climent, E. Herrero and J. M. Feliu, J. Phys. Chem. C, 2010, 114, 13802-13812.

37 C. M. Sanchez-Sanchez, J. Solla-Gullon, F. J. Vidal-Iglesias, A. Aldaz, V. Montiel and E. Herrero, J. Am. Chem. Soc., 2010, 132, 5622-5624.

38 E. Schmidt, W. Kleist, F. Krumeich, T. Mallat and A. Baiker, Chem.-Eur. J., 2010, 16, 2181-2192.

39 S. O. Blavo, E. Qayyum, L. M. Baldyga, V. A. Castillo, M. D. Sanchez, K. Warrington, M. A. Barakat and J. N. Kuhn, Top. Catal., 2013, 56, 1835-1842.

40 J. M. Krier, W. D. Michalak, L. R. Baker, K. An, K. Komvopoulos and G. A. Somorjai, J. Phys. Chem. C, 2012, 116, 17540-17546.

41 P. S. Fernandez, D. S. Ferreira, C. A. Martins, H. E. Troiani, G. A. Camara and M. E. Martins, Electrochim. Acta, 2013, 98, 25-31.

42 F. J. Vidal-Iglesias, J. Solla-Gullon, E. Herrero, V. Montiel, A. Aldaz and J. M. Feliu, Electrochem. Commun., 2011, 13, 502-505.

43 S. E. Lohse, N. D. Burrows, L. Scarabelli, L. M. Liz-Marzan and C. J. Murphy, Chem. Mater., 2014, 26, 34-43. 
44 T. S. Ahmadi, Z. L. Wang, T. C. Green, A. Henglein and M. A. El-Sayed, Science, 1996, 222, 1924-1926.

45 J. S. Bradley, B. Tesche, W. Busser, M. Maase and M. T. Reetz, J. Am. Chem. Soc., 2000, 122, 4631-4636.

46 T. Herricks, J. Chen and Y. Xia, Nano Lett., 2004, 4, 23672371.

47 X. Teng and H. Yang, Nano Lett., 2004, 4, 2367-2371.

48 B. Zhang, D. Wang, Y. Hou, S. Yang, X. H. Yang, J. H. Zhong, J. Liu, H. F. Wang, P. Hu, H. J. Zhao and H. G. Yang, Sci. Rep., 2013, 3, 1836.

49 C. K. JØrgensen, Acta Chem. Scand., 1956, 10, 518-534.

50 B. Corain and A. J. Poe, J. Chem. Soc. A, 1967, 329, 1633-1641.
51 V. Climent, R. Gomez, J. M. Orts and J. M. Feliu, J. Phys. Chem. B, 2006, 110, 11344-11351.

52 A. B. Anton and D. C. Cadogan, Surf. Sci., 1990, 239, L548L560.

53 S.-B. Zhu, Surf. Sci., 1995, 329, 276-284.

54 A. Kuzume, Y. Mochiduki, T. Tsuchida and M. Ito, Phys. Chem. Chem. Phys., 2008, 10, 2175-2179.

55 M. L. Lynch and R. M. Cave, J. Phys. Chem., 1990, 94, 43824385.

56 D. Zurawski, L. Rice, M. Hourani and A. Wieckowski, J. Electroanal. Chem., 1987, 230, 221-231. 